Article

\title{
Visual Language-Aided Construction Fire Safety Planning Approach in Building Information Modeling
}

\author{
Numan Khan, Ahmed Khairadeen Ali, Si Van-Tien Tran, Doyeop Lee * and Chansik Park * \\ School of Architecture and Building Science, Chung Ang University, Seoul 06974, Korea; \\ numanpe@gmail.com (N.K.); ahmedshingaly@gmail.com (A.K.A.); Tranvantiensi1994@gmail.com (S.V.-T.T.) \\ * Correspondence: doyeop@cau.ac.kr (D.L.); cpark@cau.ac.kr (C.P.)
}

Received: 31 December 2019; Accepted: 26 February 2020; Published: 2 March 2020

\begin{abstract}
Fires pose an enormous threat to human safety and many spectacular fires in under-construction buildings were reported over the past few years. Many construction sites only rely on fire extinguishers, as under-construction buildings do not contain a permanent fire protection system. Traditional safety planning lacks a justified approach for the firefighting equipment installation planning in the construction job site. Even though many government agencies made safety regulations for firefighting equipment installations, it is still a challenge to translate and execute these rules at the job site. Currently, the construction industry is devoted to discovering all the possible applications of Building Information Modelling (BIM) technology in the entire phases of the project life cycle. BIM technology enables the presentation of facilities in 3-D and offers rule-based modeling through visual programming tools. Therefore, this paper focuses on a visual language approach for rule translation and a multi-agent-based construction fire safety planning simulation in BIM. The proposed approach includes three core modules, namely: (a) Rule Extraction and Logic Development (RELD) Module, (b) Design for Construction Fire Safety (DCFS) Module, and (c) Con-fire Safety Plan Simulation (CSPS) Module. In addition, the DCFS module further includes three submodules, named as (1) Firefighting Equipment Installation (FEI) Module, (2) Bill of Quantities (BoQs) for firefighting Equipment (BFE) Module, and (3) Escape Route Plan (ERP) Module. The RELD module converts the OSHA fire safety rule into mathematical logic, and the DCFS module presents the development of the Con-fire Safety Planning approach by translating the rules from mathematical logic into computer-readable language. The three sub-modules of the DCFS module visualize the outputs of this research work. The CSPS module uses a multi-agent simulation to verify the safety rule compliance of the portable firefighting equipment installation plan the system in a BIM environment. A sample project case study has been implemented to validate the proof of concept. It is anticipated that the proposed approach has the potential to helps the designers through its effectiveness and convenience while it could be helpful in the field for practical use.
\end{abstract}

Keywords: fire safety rule; visual language; building information modeling; portable firefighting equipment

\section{Introduction}

The construction sector includes many unhealthy and unsafe activities, which lead to discouraging workers, delay project progress, affect the cost, reduce productivity, damage reputation and eventually cause human fatalities and injuries [1]. Despite much efforts, construction job sites are still known to be one of the hazardous worksites due to high accidents rate, and thus construction safety remains a vital issue in many countries. Among the construction site accidents, fires pose a significant threat to human safety. Fire safety management must be a concern for every business, but it is particularly important 
in construction since sites under construction are often at high risk of fire due for several reasons. First, workers usually are exposed to combustible substances, and the presence of wind around the unfinished buildings can immediately cause a fire [2]. Secondly, construction sites only rely on fire extinguishers or sometimes water tanks, as under-construction buildings do not possess permanent and adequate fire protection systems [3]. Thirdly, the unique nature of the construction industry is the reasons for high risks, such as a complex working environment, a certain amount of wastes, unskilled workers, and many other hazards itself [4].

Many people become seriously injured or die due to fire accidents each year [5]. Fire incidents came into existence with the use of fire after its discovery and are intimately related to the progression of human civilization [6]. Regarding the general statistics of fire accidents, the World Health Organization (WHO) reported deaths of more than 300,000 people annually by fire-induced burns. Unfortunately, disturbing statistics are that 95 percent or more of these deaths happen in low-income and middle-income countries [5]. According to the recent report published in Bureau of Labor statistics in 2019, fire and explosion were responsible for 115 workplace deaths in 2018 and 123 deaths in 2017, which is slightly higher than the 88 fatalities recorded in 2016 [7]. The data published in 2018 by the U.S Bureau of Labor Statistics stated that every year, 66 construction workers are killed due to fires and explosion [8]. The National Fire Protection Association (NFPA) carried out a five-year (2010-2014) study on under construction or renovation residential projects (discounting one- and two-unit projects) and found $\$ 280$ million of direct damage to the property each year [4].

The growing challenges for fire safety concerning economic progress have encouraged the evolution of fire science and technology [6]. The primary aim of fire science and technology in the early time was to protect properties (to save large factories mainly) and avoid sweeping fires conflagration in cities [9]. Ample research has been performed considering fire safety monitoring and early detection. Many studies have been carried out for detecting smoke and by using different technologies such as very early smoke detection apparatus (VESDA), Dual infrared (IR/IR) spectral band flam detection, fiber optic attached to distributed temperature sensing (DTS) and linear infrared flammable gas detection. $[6,10,11]$. Apart from fire safety monitoring and fire detection, several studies have also focused on fire safety and evacuation planning for buildings and tunnels [12-15]. To overcome the issue of fire safety in an existing building, fire safety evaluation systems for fire prevention, evacuation, and mitigation strategies were studied [13]. Advancements in fire safety science concerning modern-day buildings have gradually urged for the integration of fire safety in the design, yet, very few studies investigated fire safety during the planning and design stage. Wang et al. developed a BIM-based safety management model for escape route planning, fire safety education, and maintenance records of fire equipment are in buildings [16]. Another study integrated BIM with fire dynamics simulator for a personal safety evaluation and escape route plan [17].

Currently, it is evident that many designers do not consider fire safety in the iterative design process of buildings, thus, the merging of fire safety science with the design process has the enormous potential [18]. Also, recent research has depicted that many construction accidents are associated with the design that could be eliminated with appropriate design considerations $[19,20]$.

Equipment operators, electric technicians, carpentry trades, HVAC mechanics, and many other trades are all prone to construction burn injuries and explosion accidents, which could be prevented. The probability of overcoming fire accidents could be increased if fire safety planning is incorporated in the design phase and implement during construction. The quantity of industrial and civil construction projects is rapidly increasing due to socioeconomic development policies and urbanization in many countries [21]. To make sure the fire and rescue operation is practical and useful as possible is a significant task for any building contractor [22]. Very few researches studied fire safety management planning in the design phase, but the firefighting equipment safety plan is not yet discovered. Thus, there is a gap identified in the literature for the portable firefighting equipment safety plan consideration in the design phase. 
Likewise, many construction job sites, unfortunately, do not apply the safety rule-based fire safety planning for portable firefighting equipment installation. The Occupational Safety and Health Administration (OSHA) stipulates that the site-specific safety plan should include a fire protection plan for every construction project [23]. In case of fire during the construction phase, the workers in the job site must be aware of escape routes and necessary relevant information about the fire extinguisher. The vital factor is to ensure the equipment is perfectly located and in good order. The scope of this paper is limited to the appropriate placement of the firefighting equipment, while the perfect order issue will be addressed in another research paper. In order to enhance the construction fire safety planning, this paper proposed a safety rule-based visual programming approach for the appropriate portable firefighting equipment installation plan. Figure 1 explains the conceptual framework for the fire safety planning in construction, which is named as the Con-fire Safety Planning (CSP) approach. Related safety rules for portable firefighting equipment's installation are extracted from the construction best practices and OSHA database. As depicted in Figure 1, visual programming is employed to translate the safety rule into machine-readable language, which provides the four outputs: (1) portable firefighting equipment installation plan, (2) bill of quantities for the required portable firefighting equipment, (3) the multi-agent simulation to evaluates and validates the compliance of installation plan with the related OSHA safety rule. This research also integrates the escape route planning for the construction workers as well as the required quantity estimation for the portable firefighting equipment.

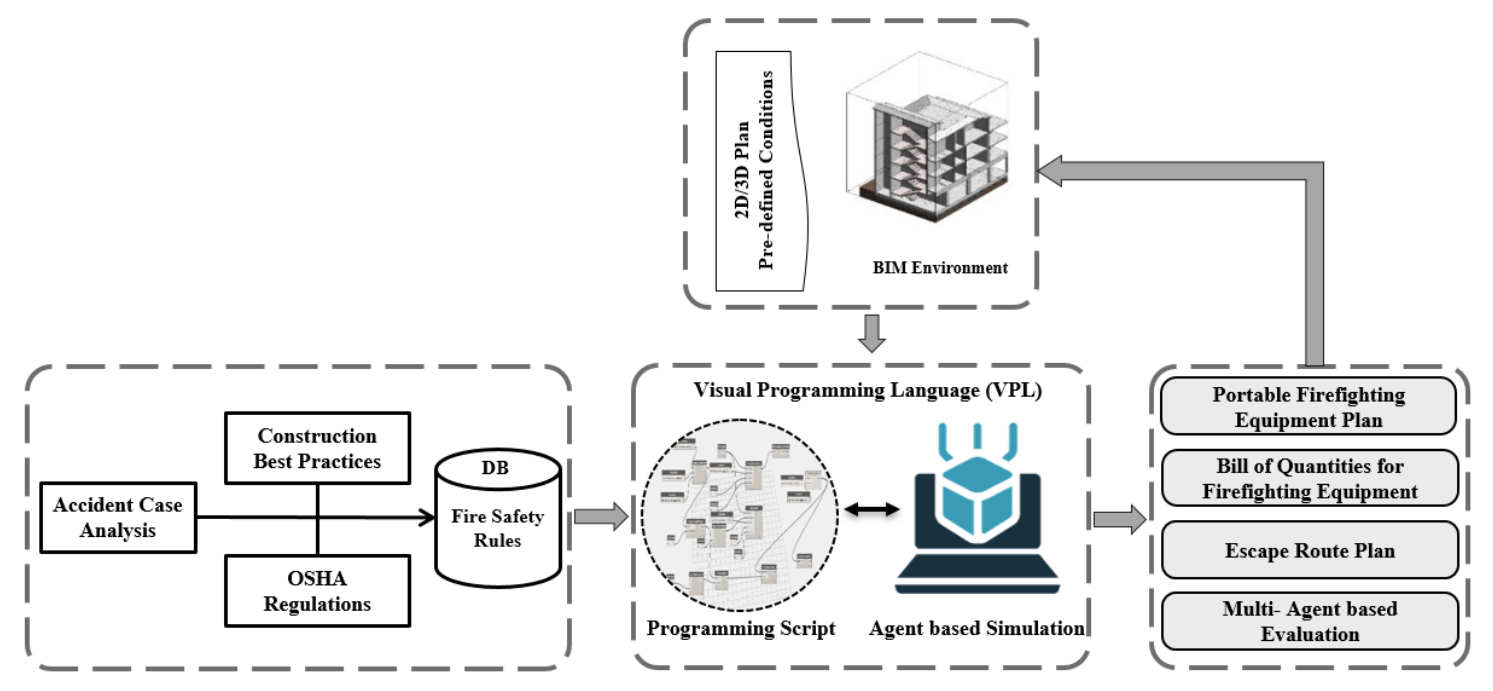

Figure 1. A conceptual framework for fire safety planning in construction.

The significance of the fire safety management, fire accident statistics, current prevention methods, gap in the current fire safety management process, and objectives (solution to the gap) of the research has already been revealed in the introduction section (see Section 1). Next, the literature review (Section 2) presents the current fire safety management status, construction safety planning and fire safety in the design phase, and advance techniques already been applied to the construction safety planning. The system framework constituent of three main modules and three submodules for prototype development. The applicability of the approach is validated through a case study detailed in Section 3. The results and limitations of the research are discussed in Section 4. Finally, this study is ended with the conclusion and future recommendations (Section 5).

\section{Fire Safety Management, Construction Planning and BIM Applications}

In this regard, to understand about the gap in the literature, fire accident and fatalities reports are reviewed with respect to the current preventive measures developed by different researchers and are summarized as current fire safety management status in construction. Insufficiencies in contemporary fire safety planning were contemplated herein with advanced techniques such as BIM 
and visual language-based design for safety concepts. Previous efforts on rule-based safety planning are thoroughly studied, and the inevitability of the proposed safety rule-based firefighting equipment installation plan is established.

\subsection{Current Fire Safety Management Status in Construction}

Occupational Safety and Health (OSHA) reported that one out of five workplace fatalities is the death of a worker from construction [24]. According to the data published by the Federal Emergency Management Agency (FEMA) of the United States (US), approximately 4800 fire accidents annually happened on construction sites [25]. The fire safety engineering emerged in the early 20th century as a response to the fire problem caused by the industrial revolution [6]. The growing urbanization and socioeconomic development reflected an increase in the construction of industrial and civil projects. In recent years, the fire in construction projects was frequently witnessed, and some of them have brought a considerable loss of casualties and property damage [21].

In order to tackle the fire safety problem after the number of severe accidents, several countries around the globe have adopted a series of activities such as fire provisions, fire safety inspections, and up-gradation of fire safety codes [26]. Many early warning systems with different technological approach has been developed for the detection of heat and smoke such as Very Early Smoke Detection Apparatus (VESDA) [10], and Cygnus wireless alarm system [27]. A safe evacuation plan for human is very crucial during fire accidents. BIM-based disaster prevention management system was developed by offering built-in functions such as escape route planning, training, and maintenance record keeping feature for fire safety equipment [17]. In order to understand human behavior during burning tragedies and evacuation, a BIM-based serious human rescue game simulation method was proposed [28]. Generally, construction projects include a vast number of complicated tasks with a tight schedule and fire safety provisions [29]. To ensure the safety from fire in complex buildings, escape routes planning and fire extinguishers are just used to save oneself [15]. Computational Fluid Dynamics (CFD) has been applied to assess the internal condition of the construction workplace during the fire situation [30]. To meet the fire safety requirement, the CFD method is currently common in the design process of construction work. Liu et al. proposed an index system based on-site specification for fire hazard assessment in construction using the fuzzy mathematical method [21].

\subsection{Construction Safety Planning and Fire Safety}

Fire safety planning holds a key position in the domain of construction safety planning. However, fire safety planning is carried out separately from the project design phase. In the construction industry, the provision of portable firefighting equipment is considered the sole obligation of the contractor [31]. Currently, the construction industry follows site-specific fire safety planning practices [32,33], which need to be reviewed and updated with intervals [34]. Consequently, comprehensive fire safety planning that includes escape route plans, firefighting equipment installation plans, and mandatory education for workers can be an enormously labour-intensive job if done manually. Therefore, updated and practical fire safety plans are not provided in many construction projects [35].

Emerging technologies such as big data, BIM and other computer-aided simulations offer new ways to improve construction safety planning [36]. In order to enhance traditional construction safety management, many researchers have contributed the elementary research studies towards the design for safety concepts [19,36-39]. For instance, a tool to support the hazard identification inherited in the construction process and component, named as design for safety process (DFSP), has been developed by Hadikusmo and Rowinson [40]. Zhang et al. developed a BIM-based safety rule checking system to identify fall hazard through automated checking of 3D models in the design phase. To enhance construction safety planning in the design phase, another study from the same author proposed ontology-based semantic modeling for safety knowledge [41]. A safety rule-based modeling approach 
has been applied to deal with the excavation related risks, such as cave-in, fall, prohibited zone identification, egress, and ingress [19].

On the contrary, some studies have focused on the BIM application in the design for fire evacuation assessment [17], equipment maintenance, escape route planning, and safety education [16]. However, there is a lake of integration for firefighting equipment installation planning and its integration with fire safety management. Hence, the OSHA rule-based visual language approach is developed to enrich construction fire safety planning.

\subsection{BIM and Visual Languages}

Generally, the safety management process comprises two aspects, namely safety planning and safety monitoring. Surprisingly, safety planning is generally considered the contractor's liability and thus usually gets ignored in the design phase. However, this concept is being changed due to extensive studies recently considered new technologies such as Building Information Modelling. BIM is actively applied to develop rule-based checking systems for building permits [42]. Many studies have currently developed various algorithms to improve safety planning using BIM-based automatic safety rule checking for unsafe design [43], excavation safety modeling [19], BIM-based scaffolding planning [44], and schedule integrated limited access zone identification and visualization [41]. However, fire safety planning has yet covered education and escape route planning so far.

To translate Korean natural language into computer-readable language, the Korean government has developed KBimCode rule interpretation authoring plug-in, as a part of research [45]. Instead of a hard-coded approach for text-based rule translation into computer understandable language, visual language approaches and parametric input tables have been adopted in different studies recently, such as KBimcode [42], Auto-Exca safety modeling [19], and automated scaffolding risk analysis using BIM [46]. On that account, this research work also utilized the visual language for the development of fire safety management system for construction.

\subsection{Need for Rule-Based Firefighting Equipment Installation Plan}

The previous efforts on fire safety management and have been reviewed to understand about the accidents and its prevention methods. With this regard, it is concluded that the construction industry currently is focusing on disaster prevention management, which includes escape route planning, fire safety equipment, and educational training intended to ensure the personal safety of individuals [17]. However, conventional disaster prevention methods still depend on manual operating procedures, which is cumbersome. For instance, as a permanent fire safety prevention system that is usually available in build buildings do not exist in many construction job sites. So, they utterly rely on fire extinguishers or water tanks. Average people do not easily understand the correct position for those fire extinguishers in a job site. In the last decade, extensive studies have been carried out by various researchers which reveal the absence of reactive tools to support designers regarding safety in construction [38]. Traditionally, the designer remains surprisingly not aware about the impact of fire safety considerations in the design stage [18]. However, recent advances in fire safety management have disclosed the potential value of fire safety in the design stage. Therefore, a more creative and user-friendly solution is required to sort out the issue. To do so, considering fire safety equipment planning and appropriate allocation in the design stage is inevitable.

\section{Structure of Con-fire Safety Planning Approach}

The propose system framework for Con-fire Safety Planning Approach consists of three main modules, as revealed in Figure 2, namely: (a) Rule Extraction and Logic Development (RELD) Module, (b) Design for Construction Fire Safety (DCFS) Module, and (c) Con-fire Safety Plan Simulation (CSPS) Module. As depicted by Figure 2, the RELD module is intended to extract the fire safety rules and offer the mathematical structure to the DCFS module. The DCFS module converts mathematical information to computer-readable data by using visual programming tools. This module further 
includes three sub-modules, named as (1) Firefighting Equipment Installation (FEI), (2) BoQs for firefighting Equipment (BFE), and (3) Escape Route Plan (ERP). The three main modules depict the entire process overview of the Con-fire Safety Planning approach, while the three sub-modules profoundly illustrate the DCFS module. The functions and systematic process of the proposed approach in each module are described in the subsequent sections.

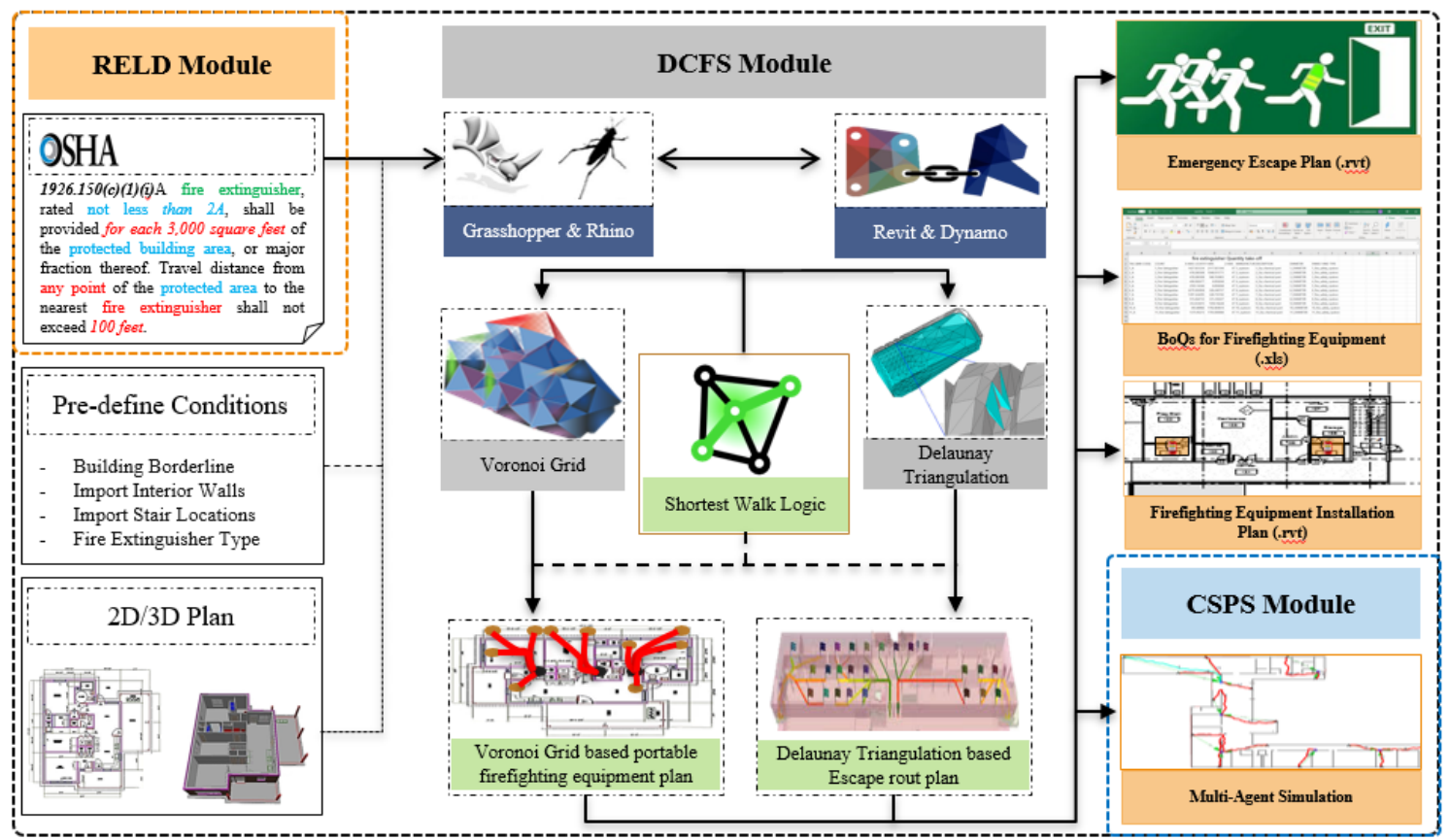

Figure 2. System architecture for Con-fire safety planning approach.

\subsection{Rule Extraction and Logic Development (RELD) Module}

Accident reports offer vital information such as root causes, responsible roles, and recommended preventive techniques for the avoidance of future accidents. To understand the fire hazards and its preventive methods in construction, this research work was initiated with the assessment of accident reports. Deployment of portable firefighting equipment was found the crucial preventive measure in case of typical under-construction works, while installation of the sprinkler system was noticed vital for fire-sensitive projects such as steel-related projects and tunnels.

In order to ensure a safe environment in terms of fire mishaps, OSHA regulations for fire protection and prevention are investigated in the second step. The safety-related fire regulations have been extracted from the OSHA database. These regulations provide lessons learned from the past and current best practices to minimize the probability of accidents in the construction workplace. Table 1 . revealed the OSHA standard number 1926, which describes the related safety and health regulations to the construction industry. Fire protection and prevention rules are depicted under the subpart-F of construction safety and health standard (1926). The standard number 1926.150 demonstrates the fire protection rules, which include general requirements, water supply, portable firefighting equipment, fixed firefighting equipment, and fire alarm devices, as listed in Table 1.

Portable firefighting equipment plays a significant role to deal with the construction fire, as many job sites do not contain permanent firefighting systems [3]. Since the distance between the portable firefighting equipment with the persons working in the area also influence the reactive time required to control the fire when it is in the initial stage, OSHA construction fire standards specify the limit of the distance between the persons and firefighting equipment. According to OSHA, "A fire extinguisher, rated not less than $2 \mathrm{~A}$, shall be provided for every 3000 square feet of the protected building area, or major fraction thereof. Travel distance from any point of the protected area to the nearest fire 
extinguisher shall not exceed 100 feet." To limit the scope of the work, this paper merely considers portable firefighting equipment planning for further research. Apart from that, this research also generates an escape plan as an employee emergency route plan. The manually extracted regulations relevant to fire protection are converted into mathematical logics from text-based information, which is then employed for visual programming in the Design for Construction Fire Safety (DCFS) Module. The following conditions are extracted from the OSHA fire safety rules for construction.

(1) Placement of at least one fire extinguisher of type, rated not less than $2 \mathrm{~A}$, for the area of 3000 square feet.

$$
2 A=\frac{\text { Total Protected Area }}{3000}
$$

(2) The distance from any point of the protected area to the nearest fire extinguisher should be less than or equal to 100 feet while using the fire extinguisher type, rated not less than $2 \mathrm{~A}$.

$$
\text { Distance from any point } \leq 100 \text { feet for rated } \geq 2 A
$$

(3) In the case of using a fire extinguisher, rated not less than 10B, the distance from any point of the protected area to the closest fire extinguisher should be less than or equal to 50 feet.

Distance from any point $\leq 50$ feet for rated $\geq 10 B$

\begin{tabular}{|c|c|c|}
\hline \multicolumn{3}{|c|}{ 1926-Safety and Health Regulations for Construction } \\
\hline \multicolumn{3}{|c|}{1926 Subpart F-Fire Protection and Prevention } \\
\hline No. & Standards & Explanation \\
\hline 1926.150(a) & General requirements & $\begin{array}{l}\text { This standard explains the employer responsibility of fire protection } \\
\text { plan, conspicuously location of firefighting equipment's and its periodic } \\
\text { check to assure protection of life }\end{array}$ \\
\hline 1926.150(b) & Water supply & $\begin{array}{l}\text { This standard focuses on the requirements of the fixed or temporary } \\
\text { water supply of enough volume and pressure or either completely } \\
\text { installed underground water mains. }\end{array}$ \\
\hline $1926.150(\mathrm{c})$ & Portable firefighting equipment & $\begin{array}{l}\text { This article explains the vital part that determines the location criteria } \\
\text { for firefighting equipment based on its types. }\end{array}$ \\
\hline 1926.150(d) & Fixed firefighting equipment & It focuses on rules related to the installation of fixed sprinkler protection. \\
\hline $1926.150(\mathrm{e})$ & Fire alarm devices & $\begin{array}{l}\text { This part considers the establishment of an alarm system and } \\
\text { communication systems with the local fire department. }\end{array}$ \\
\hline
\end{tabular}

Table 1. Fire Protection and Prevention related to OSHA regulations.

\subsection{Design for Construction Fire Safety (DCFS) Module}

The Design for Construction Fire Safety (DCFS) module is a significant module of this research work. This section is devised to convert mathematical logics into computer-readable data, which is obtained from the Rule Extraction and Logic Development (RELD) module. Figure 2 illustrates the system architecture for the Con-fire Safety Planning approach. A commercially available Visual programming language (VPL) tools, named as Grasshopper (BIM authoring platform and a plug-in for Rhinoceros) and Dynamo (BIM authoring platform and a plug-in for Autodesk Revit) were availed to achieve the task of rule conversion. Visual programming is employed in this research study due to several reasons. It is relatively convenient to use as compared with other programming languages [19] such as python, java, and many more. This language effectively represents the information flow through visual symbols (nodes and connections) [42] with precise inputs and outputs. Therefore, this paper proposed a visual language approach for the translation of fire safety rules, which is established from the subpart F (Fire Protection and Prevention) of the OSHA-1926. This module further contains three submodules of the proposed approach. 


\subsubsection{Design for Firefighting Equipment Installation (FEI) Module}

This subsection focuses on fire protection and leverages the visual language approach to acquire BIM-based portable firefighting equipment safety planning in construction. The script is initiated with the extraction of geometric data as input from the 2D plan. As depicted in Figure 3, the method allows the user to define the following four (U1, U2, U3 and U4) conditions: $\mathrm{U} 1$ is importing building borderlines (BL) as a 2D plan geometry, $\mathrm{U} 2$ is to determine the plan interior walls (IW) as a $2 \mathrm{D}$ line geometry, U3 is to define stair locations (SL) as pick points, and U4 is intended to choose fire extinguisher type from the dropdown list that includes type 2A and 10B. According to the OSHA rules, 1926.150(c)(1)(i) A fire extinguisher, rated not less than 2A, shall be provided for every 3,000 square feet of the protected building area, or significant fraction thereof. Travel distance from any point of the protected area to the nearest fire extinguisher shall not exceed 100 feet. Where the Dividing Distance of 2A (DDA) fire extinguisher type is $100 \mathrm{ft}$, and the area is 3000 square feet. Similarly, The OSHA article 1926.150(c)(1)(vi) revealed the Dividing Distance of rated not less than 10B (DDB) fire extinguisher type is 50 feet.

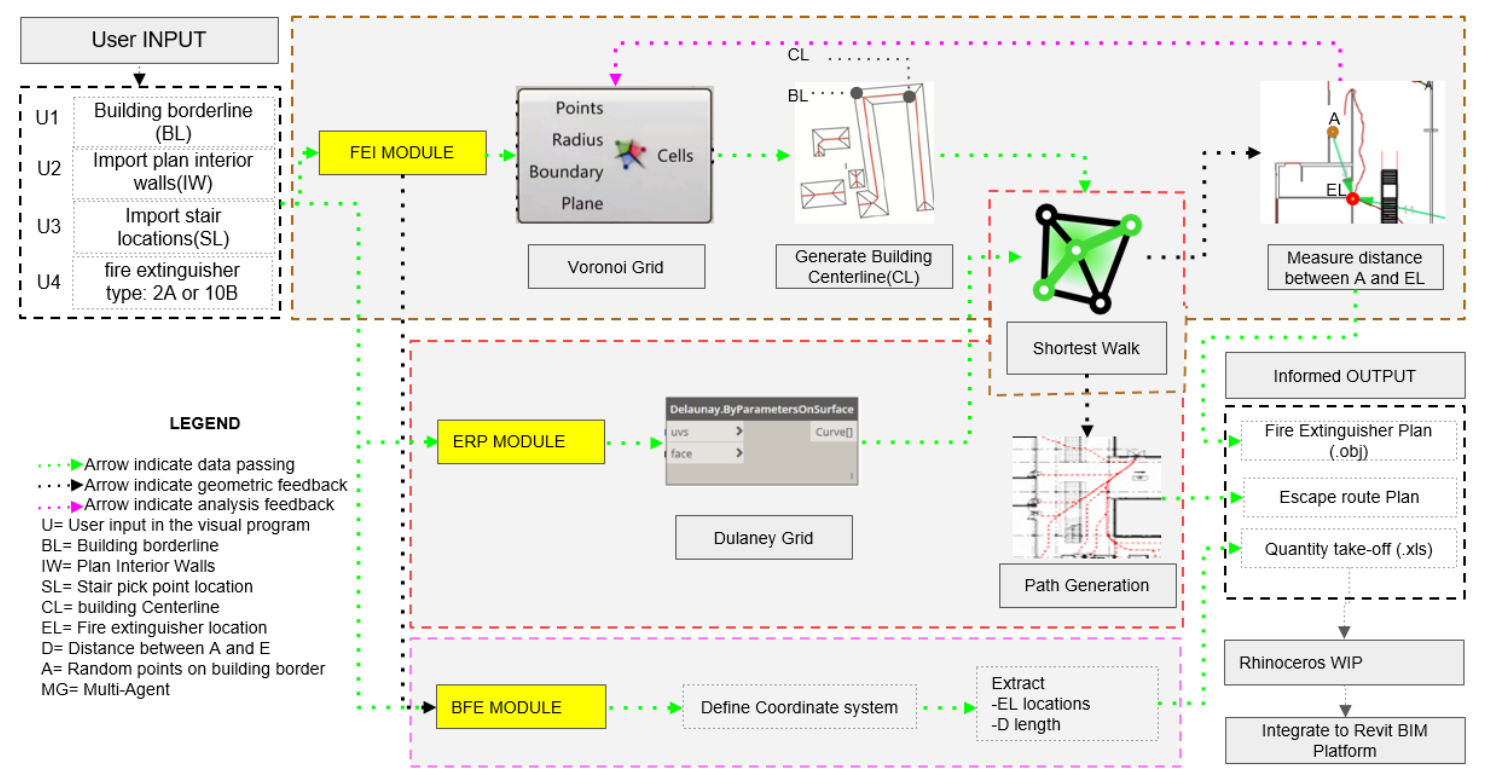

Figure 3. System architecture for Con-fire safety planning approach.

In the FEI Module, the algorithm uses the Voronoi Grid to generate a building centerline (CL), as shown in Figure 3. The building centerline (CL) used in this research refers to a $2 \mathrm{D}$ line located in the center of a closed curve of the building borderline (BL). To generate the fire extinguisher's initial locations, the program divides the building centerline by the number of the fire extinguisher obtained from the division of the surface area of the building and the advised required area by OSHA, which is 300 square feet. Thereafter, these initial locations are moved to their closest interior walls (IW) in order to create a fire extinguisher location (EL). The algorithm divides building borderline (BL) into a random number of points (A) to test the shortest walk distance between BL and EL. The algorithm verifies the appropriate location of the fire extinguishers by using the shortest walk logic. The shortest walk logic is a pre-designed component in the visual programming tool (grasshopper). It populates the building surface geometry with points then creates connection lines between points using proximity two-dimensional logic. After that, the algorithm calculates the shortest walk between the locations of random points A and their nearest fire extinguisher cluster locations (EL) and calculates a network of paths between them. The system then measures the closest route curve length (D) and evaluate it in an if statement: as, If $\mathrm{D}$ is less or equal to distance advised by the rule that could be DDA or DDB (based 
on the user selection U4), then do nothing, If $\mathrm{D}$ is higher than $\mathrm{U} 4$ then divide $\mathrm{D}$ over $\mathrm{U} 4$ and round up as illustrated in the below equation.

$$
\begin{gathered}
\text { if(D } \leq \mathrm{U} 4), \text { Return Null } \\
\text { else } \\
\text { Roundup }\left(\frac{D}{U 4}\right)
\end{gathered}
$$

Based on the result of the if statement, the algorithm considers the addition of new fire extinguisher to the existing fire extinguisher cluster. Then, the system automatically moves the fire extinguisher cluster to the closest wall (interior walls imported by the user) and moves in the z-direction by $3 \mathrm{ft}$. The algorithm creates this portable firefighting equipment plan inside the rhinoceros environment as an (.obj) file. Then this plan is integrated into the BIM model inside a commercially developed Revit program using Rhinoceros WIP add-on.

\subsubsection{BoQs for Firefighting Equipment (BFE) Module}

This submodule is envisioned to develop a creative solution for estimating the Bill of Quantities (BoQs) for portable firefighting equipment using the visual programming approach. Currently, tools for digital quantity take-off revolutionized the cost estimation aspect in the design stage by saving the time, increased accuracy, and are sophisticated enough to be used. However, to take the cost estimation process to the next level, additional concentration is needed to propose a more creative solution. To do this, a rule-based visual algorithm supported safety information model, which has a fire extinguishers placement plan obtained from the firefighting equipment installation (FEI) module.

Based on the fire extinguisher's placement plan, the system will automatically calculate the quantity take-off for the required portable firefighting equipment. The quantity take-offs list is exported to Microsoft Excel (Ms. Excel) for the cost estimation. Cost estimator and quantity surveyors with this powerful built-in function can quickly develop the required cost plan of the fire protection equipment for the project. In order to generate the quantity, take off, required data was acquired from the Firefighting Equipment Installation (FEI) Module.

The categoric process of the algorithm development for this module can be seen in Figure 3. The visual algorithm is designed to automatically extract the list of geolocations for each fire extinguisher (x-coordinates, y-coordinates, and z-coordinates) from the previous FEI module. The system will calculate the number of locations and generate quantity take-off for the fire extinguishers. The code will then merge the quantity take-off with the predefined fire extinguisher specification. The designed approach also establishes the tag codes of each fire extinguisher (see the details in the case study). The program generates the choices for the users by using the default database, such as relevant data associated with the fire extinguishers chosen by the user, such as manufacturer, family, expiry, and inspection date. As a byproduct of the proposed construction fire safety planning, the program automatically generates a bill of quantities report in excel format (.xls) and saves it on the local machine.

\subsubsection{Escape Route Plan (ERP) Module}

The purpose of this submodule is to develop the escape route plan for humans in case of an emergency evacuation. The concept of an escape route plan is not new and has been extensively studied by many researchers. An automated escape route plan establishing tools for emergency evacuation has also been developed recently in some commercially available software. The proposed approach in this paper also offers the integration of the escape route plan module. The devised script computes the escape route from the doors of the rooms towards the designated emergency exits.

The visual script developed in Dynamo, available for generation of the fire escape plan with an open application programming interface (API) is integrated with the designed approach for portable firefighting equipment plan. The dynamo script automatically extracts the level of the building as an input. The designed algorithms need few predefined conditions as inputs such as specifying circulation 
area, regular doors location, and emergency exits. The program deals with the corridor/lobby/stairs as a space family (Stairs are added separately as the category). Once the user defines and highlights the main exit, emergency exit, and staircases as a destination and click the evacuation path button, then the designed algorithm generates a grid on the interest region using the Dulaney triangulation grid method. The Dulaney triangulation is the alternate of the Voronoi grid logic and is used in the dynamo (a plug-in to the Revit). Eventually, the system applies the shortest walk logic from the regular doors to the nearest exit doors, which generate an appropriate fire escape plan and visualize back it in the Revit. The generated escape route plan can be seen in the case study.

\subsection{Con-fire Safety Plan Simulation (CSPS) Module}

The con-fire safety plan simulation module further verifies and evaluates the OSHA rule-based Con-fire Safety Planning (CSP) approach. This algorithm uses a minimalistic and lightweight crowd simulation library named as PedSim, which is based on the social forces model algorithm [47] and offers a real-time multiple pedestrian simulation in Grasshopper. In PedSim, people move from Start Gate (SG) to Destination Gate (DG), following the best route, avoiding obstacles, and other people. In this research, the Start Gate (SG) means the starting point of an agent and Destination Gate (DG) is the nearest fire extinguisher location (EL) point. The algorithm once again divides the borderline of the building (building envelope) (BL) into several points (in our case) within 100ft distance from each other and offsets them inside the building to be used as a Start Gate (SG). These points will act as start gates for Human Agent (HA), which could be increased or decreased based on user choice and the level of accuracy required for simulation. However, increasing these points (start gates) on the borderlines will reflect an increase in the computational process. The interior walls (IW) are used as obstacles for the agents to avoid in the simulation. The target destination (DG) of the agents is the closest fire extinguisher location (EL). The simulation shows the live indicators: (1)agent position, (2) the body radius, (3)velocity, (4)acceleration, (5) current path, (6) behaviors as list (6.1) maintain closeness to goal, 6.2) obstacle collision avoidance force, 6.3) anticipatory collision avoidance force, 6.4) passive collision avoidance force. The simulation generates a heat map of the agents' trace movement showing the most used corridors and paths by the agents to reach their closest fire extinguisher by using GridPersonCounter component in the grasshopper. The travel distance of any agent A (human) towards the closest portable firefighting equipment is updated in the table. In this way, we can see the traveled path of the agent, and our system shows that every generated agent is in the range of $100 \mathrm{ft}$ (1200 inches).

\section{Case Study}

This section validates a case study carried out to evaluate the approach by using a sample project from the Autodesk Revit file. The aim was to apply the Con-fire Safety Planning approach developed for portable firefighting equipment installation, bill of quantities estimation, and escape plan. Figure 4 demonstrates the Isometric view and plan of the sample project. The 2D blueprints made in Revit with the entire property's information was used for the experiment. In order to conduct the experiment in a common environment, an add-in to the Revit, Rhino WIP package was installed on the local machine. The designed visual algorithm was imported from the rhinoceros-Grasshopper to the Revit and Rhino-Grasshopper environment using the WIP package. The sample project from the Revit was opened, and exterior walls were converted into a closed curve. The stair landing locations were highlighted by a point object. The interior wall partitions were grouped as curve objects. The user chose the desired family type of the fire-extinguishers from the top-down list, such as $2 \mathrm{~A}$ or $10 \mathrm{~B}$; in our case study, we assumed 2A. Then the program generates the optimized building centerline using VORONOI grid logic. The program finds the best locations for the fire extinguishers using shortest walk logic and calculates the distance between the building envelope (border), and the fire extinguishers then add additional fire extinguishers in the area longer, outside the range of the selected 
fire extinguishers type. By pressing the run button for the fire extinguishers plan, a portable firefighting equipment installation plan is generated.

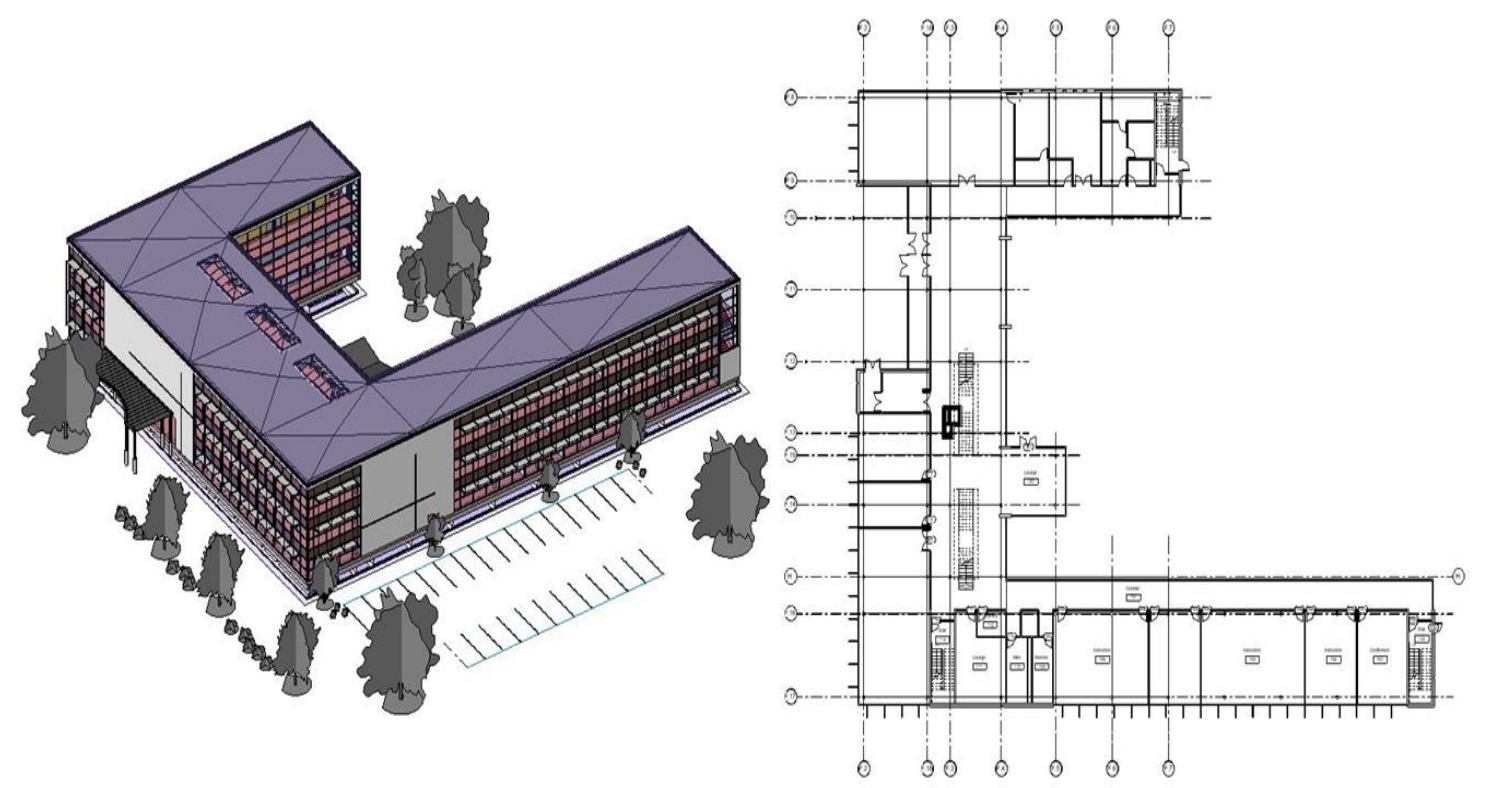

Figure 4. Isometric view and plan of Sample Project.

In order to change the shape of the building to obtain a more verified evaluation from the case study, we added one big room to the building shown in Figure 4. To further explains the process flow of the developed algorithm, the graphical illustration of the process workflow is depicted in Figure 5. This graphical illustration includes five sections. In Section 1 (S-1), the user needs to define the algorithm inputs: building outline, interior walls, stair locations, and fire extinguisher type. As illustrated in Figure 5, the intent of Section 2 (S-2) is to generate a centerline (CL) of the given building 2D plan using a Voronoi grid after evaluating the continuous line clusters among the grid collection. Subsequently, in order to locate the initial position of portable firefighting equipment, the algorithm divide centerline (CL) in several segments to generate points based on user preferences (U4 = fire extinguisher type). Afterward, the program moves the fire extinguishers to the nearest interior walls. In Section 2 of the Figure 5, the Voronoi Grid demonstrates that how the program generates proximity $2 \mathrm{~d}$ grid in the interior space surface. After that, the algorithm divides the building borderline (BL) into specific segments for the generation of random points (as mentioned in Section 3.2.1). Thereafter, the program uses the shortest walk path logic to generate the shortest path from the A points to the fire extinguisher location (EL); in this case study, we named it as point B (see Figure 5 of Section 3). Moreover, Section 3 also visualize the shortest walk from the collection of path solutions and measures the distance between the building's borderline to the fire extinguishers for further evaluation. The intention of the fourth section (S-4) is to highlight the outreach (longer) paths by using the lightweight crowd simulation library called PedSim, as an add-on in Grasshopper, a multi-agent simulation to verify the compliance of portable firefighting equipment plan with OSHA rule. In this case, the travel distance length is greater than the advised length, so the program creates an additional fire extinguisher on the longer path and moves the new fire extinguisher to the nearest wall. In the last section (S-5), the algorithm uses PedSim and GridPersonCounter component to create a heat map from the multi-agent trace for further analysis.

Figure 6 shows the multi-agent simulation results for Con-fire Safety Planning. The multi-agent simulation is adopted using the lightweight crowd simulation library named as PedSim, which is based on the social forces model algorithm. In PedSim, people move from Start Gate (A) to Destination Gate (B), following the best route, avoiding obstacles and other people, as revealed in Figure 6. The building's envelope (border) is divided into several segments with an interval of $100 \mathrm{ft}$ and offsets them inside the 
building for the purpose as a start gate (A) using the developed algorithm. The program considered interior walls (IW) as obstacles for the agents and avoided in the simulation while traveling to the destination (B) considering the closest fire extinguisher location (EL). The traveled path of the agent and our system shows that every generated agent is in the range of $100 \mathrm{ft}$ (1200 inches) except number 1, which is highlighted in the table of Figure 6.

The table highlighted the agent, which is not in compliance with the OSHA regulations. Thus, new firefighting equipment (fire extinguisher) is added to the fire extinguishers cluster, as shown in the Figures 6-8. The portable firefighting equipment plan depicts the appropriate location of the fire-extinguishers. Figure 7 shows the 3D visualization of the Con-fire Safety Planning (CSP), while Figure 8 depicts the heatmap generated after the CSP simulation.

In addition to the portable firefighting equipment installation plan, the system also generated the bill of quantities for the required equipment. A layer of firefighting equipment family is generated, and the location coordinates of the fire extinguisher are extracted from the 3D-model using visual programming. The program then automatically counts the location and export it to the excel environment. The generated excel report for the quantity take-off can be seen in Figure 9. Similarly, the algorithm automatically saves that report on the local machine of the user.

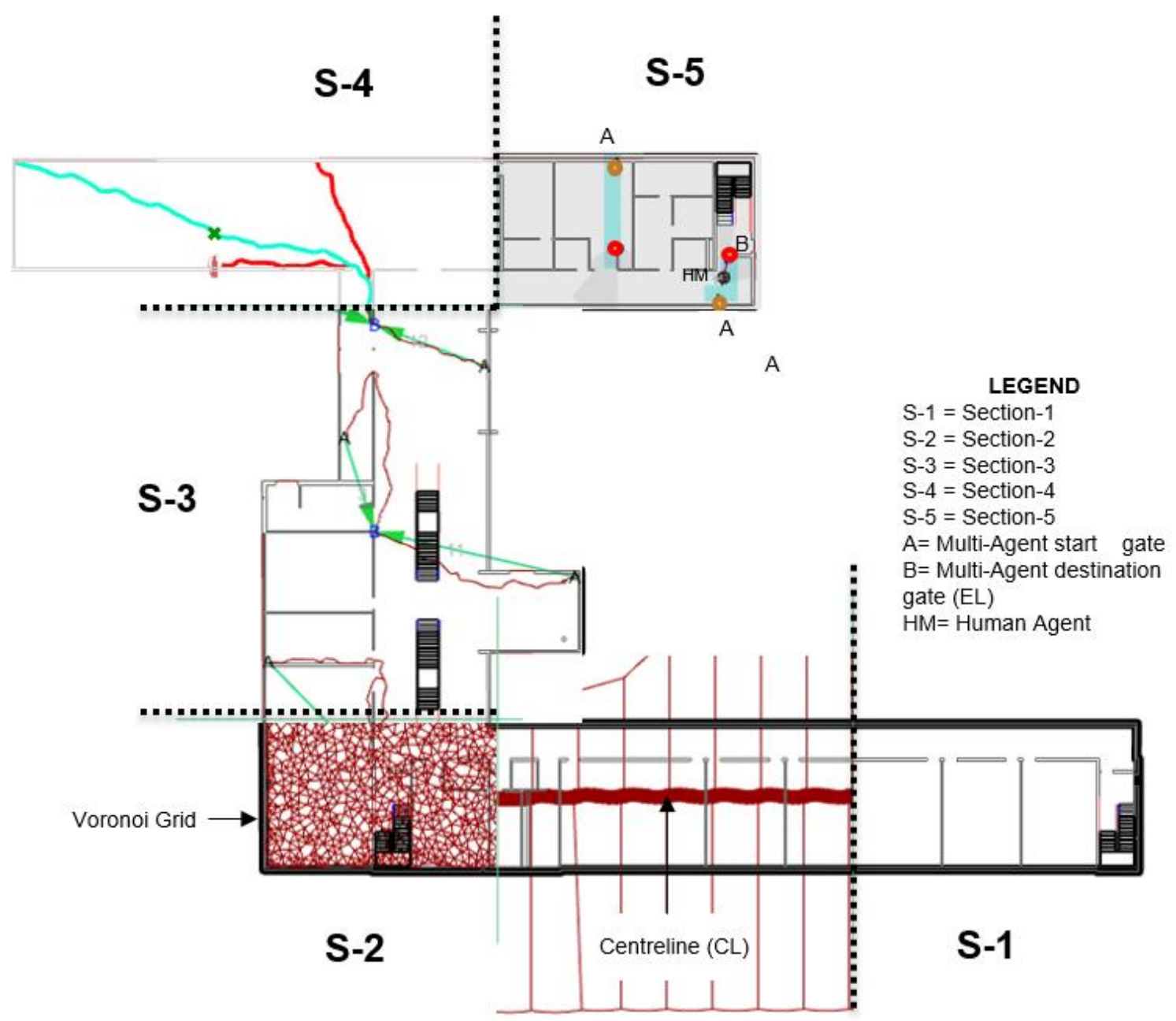

Figure 5. Graphic illustration of the process steps followed in the case study.

Correspondingly, the visual algorithm already developed for the escape route planning is applied for the purpose of finding the evacuation path. The visual code is downloaded from the GitHub and imported to the dynamo environment. The required packages were installed, and the code was simulated on the 2D plan. The system automatically generated the escape route from the regular doors 
to the defined emergency doors, as shown in Figure 10. In summary, the portable firefighting equipment installation plan and escape plan is saved as a single .obj file, while the machine automatically stored the bill of quantities as a .xls file.

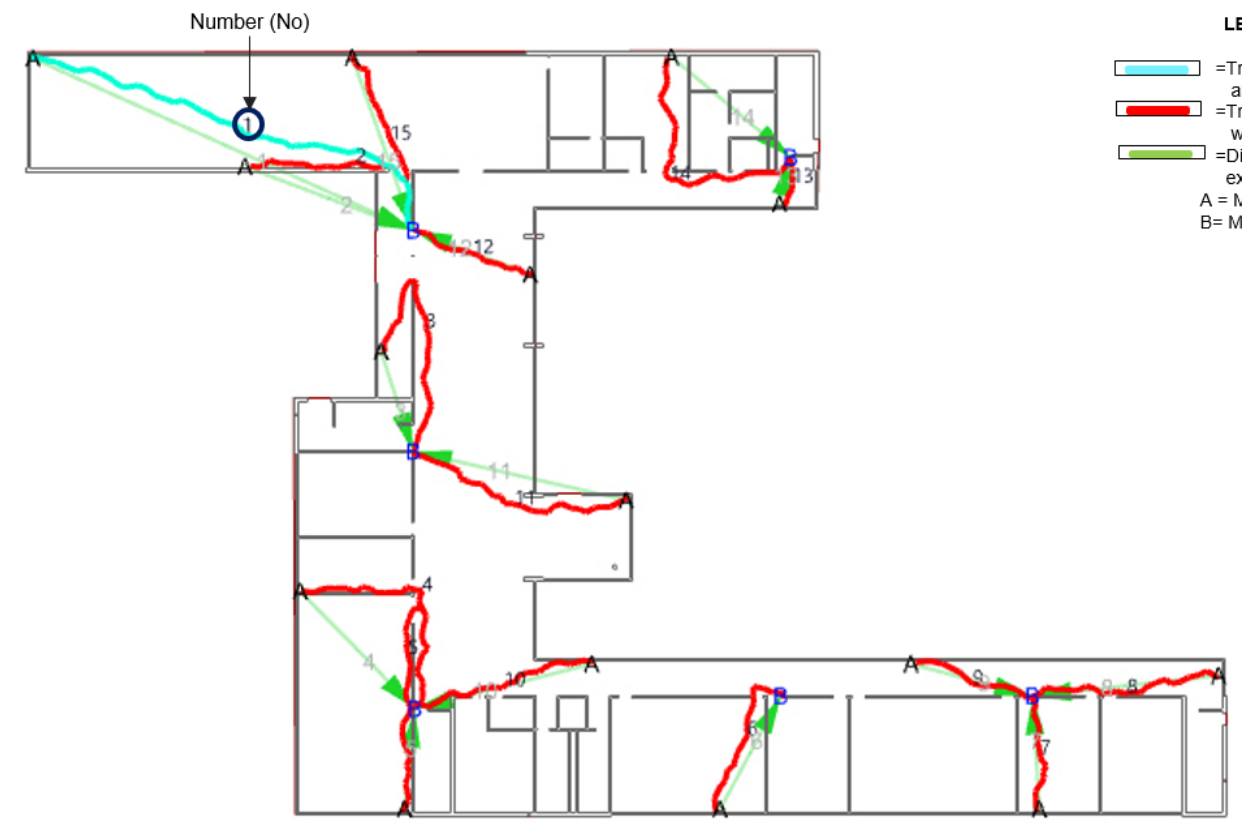

LEGEND

$=$ Travel distance longer than allowed with the rule isplacement $=$ Multi-Agent start gate $=$ Multi-Agent destination gate

\begin{tabular}{|c|c|}
\hline No & $\begin{array}{c}\text { Travel Distance } \\
\text { length (Inches) }\end{array}$ \\
\hline 1 & 1311.8 \\
\hline 2 & 610.9 \\
\hline 3 & 752.4 \\
\hline 4 & 726.7 \\
\hline 5 & 935.0 \\
\hline 6 & 488.1 \\
\hline 7 & 350.4 \\
\hline 8 & 570.0 \\
\hline 9 & 357.8 \\
\hline 10 & 559.5 \\
\hline 11 & 690.2 \\
\hline 12 & 378.6 \\
\hline 13 & 139.8 \\
\hline 14 & 752.4 \\
\hline 15 & 550.6 \\
\hline
\end{tabular}

Figure 6. Multi-Agent Simulation for the Con-fire Safety Planning.

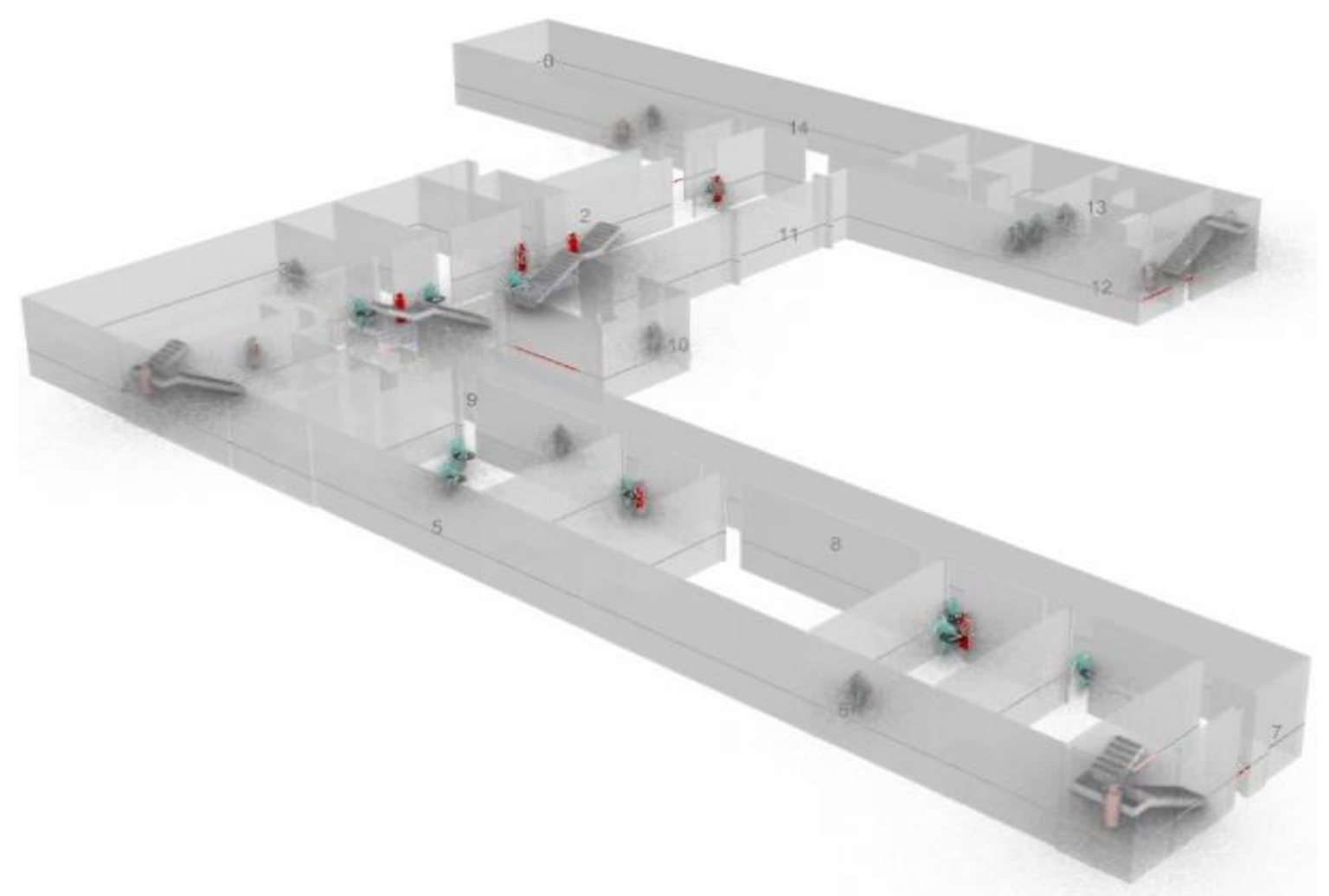

Figure 7. 3D-BIM Model of the con-fire safety planning simulation. 


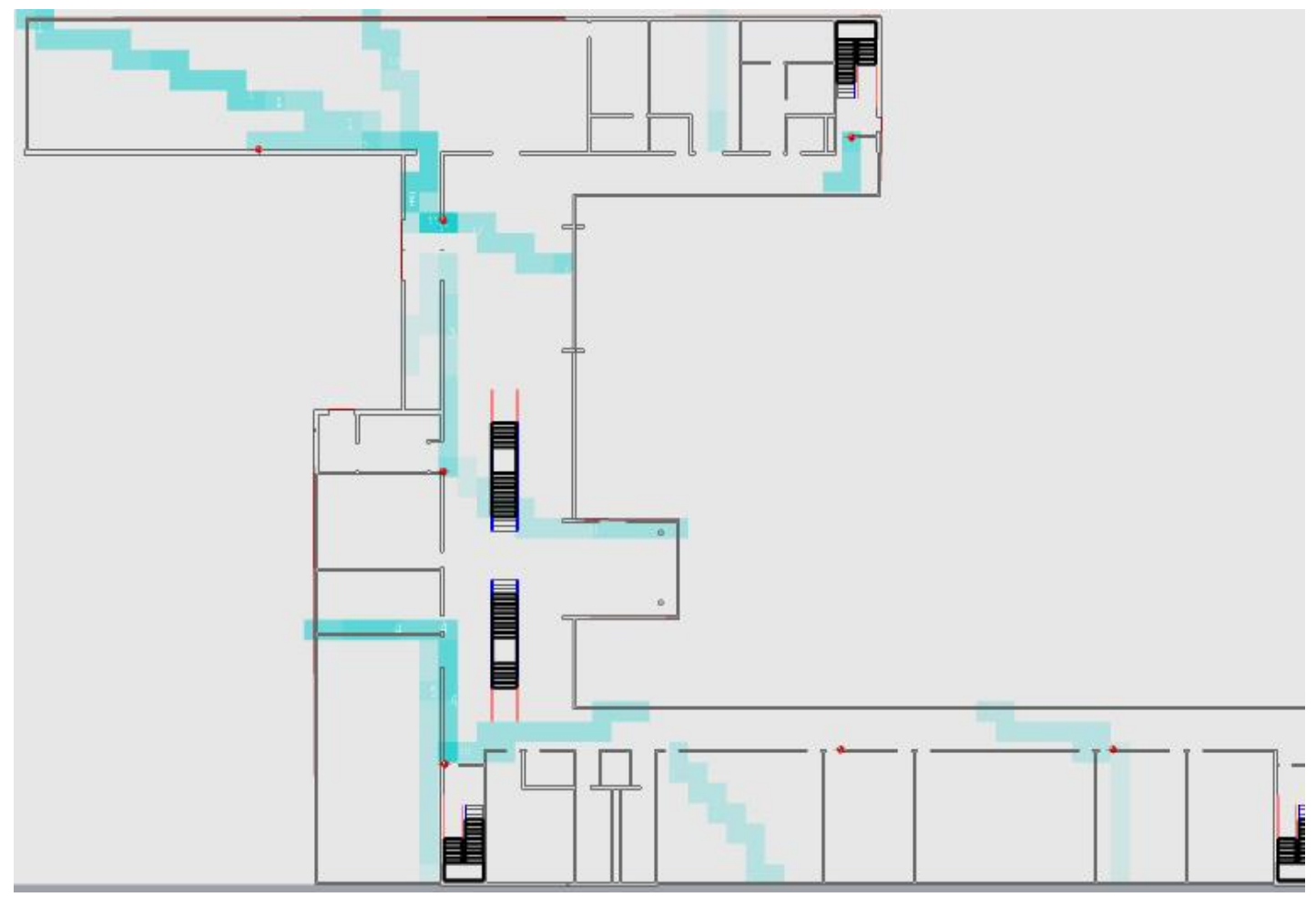

Figure 8. Heatmap of the con-fire safety planning Simulation.

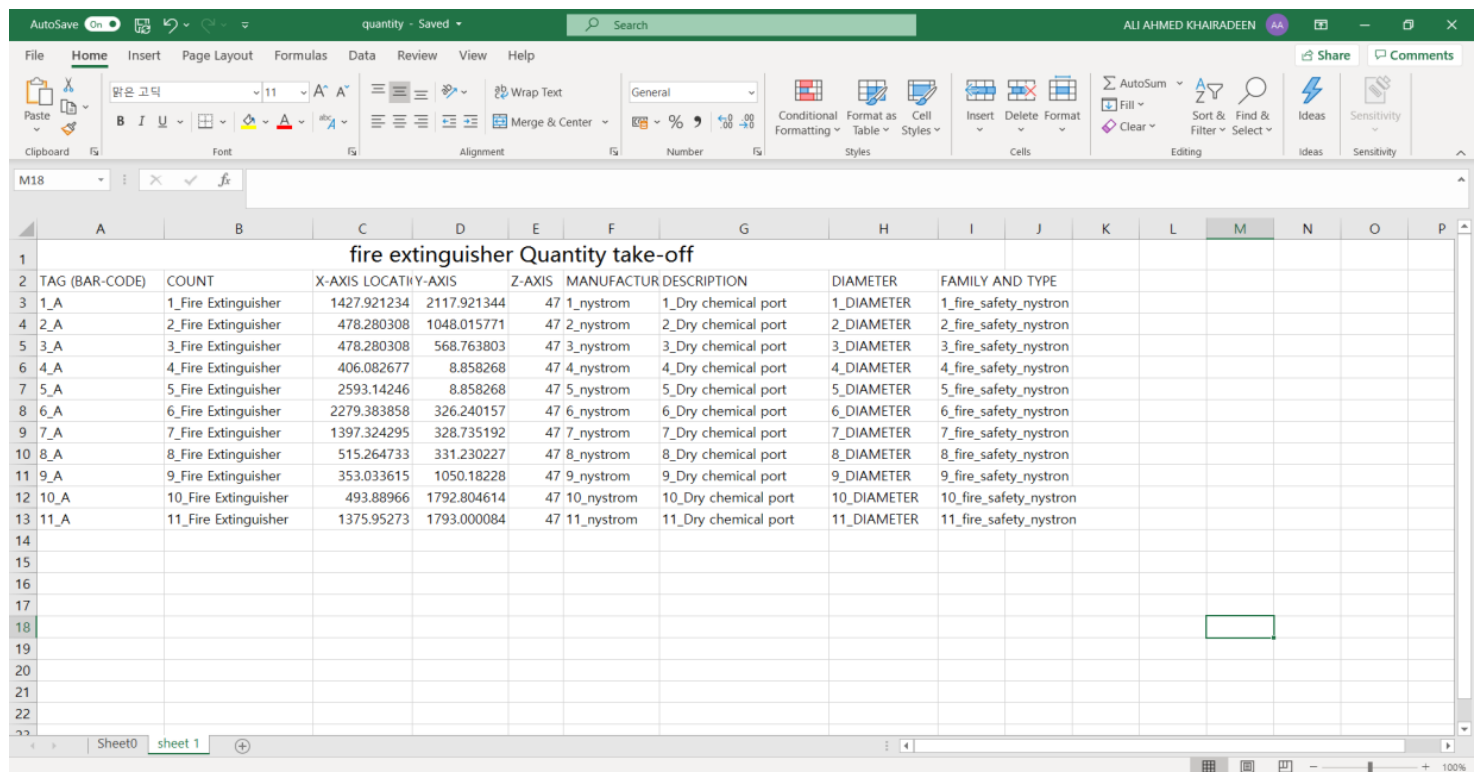

Figure 9. Bill of quantities (BoQs) for portable firefighting Equipment. 

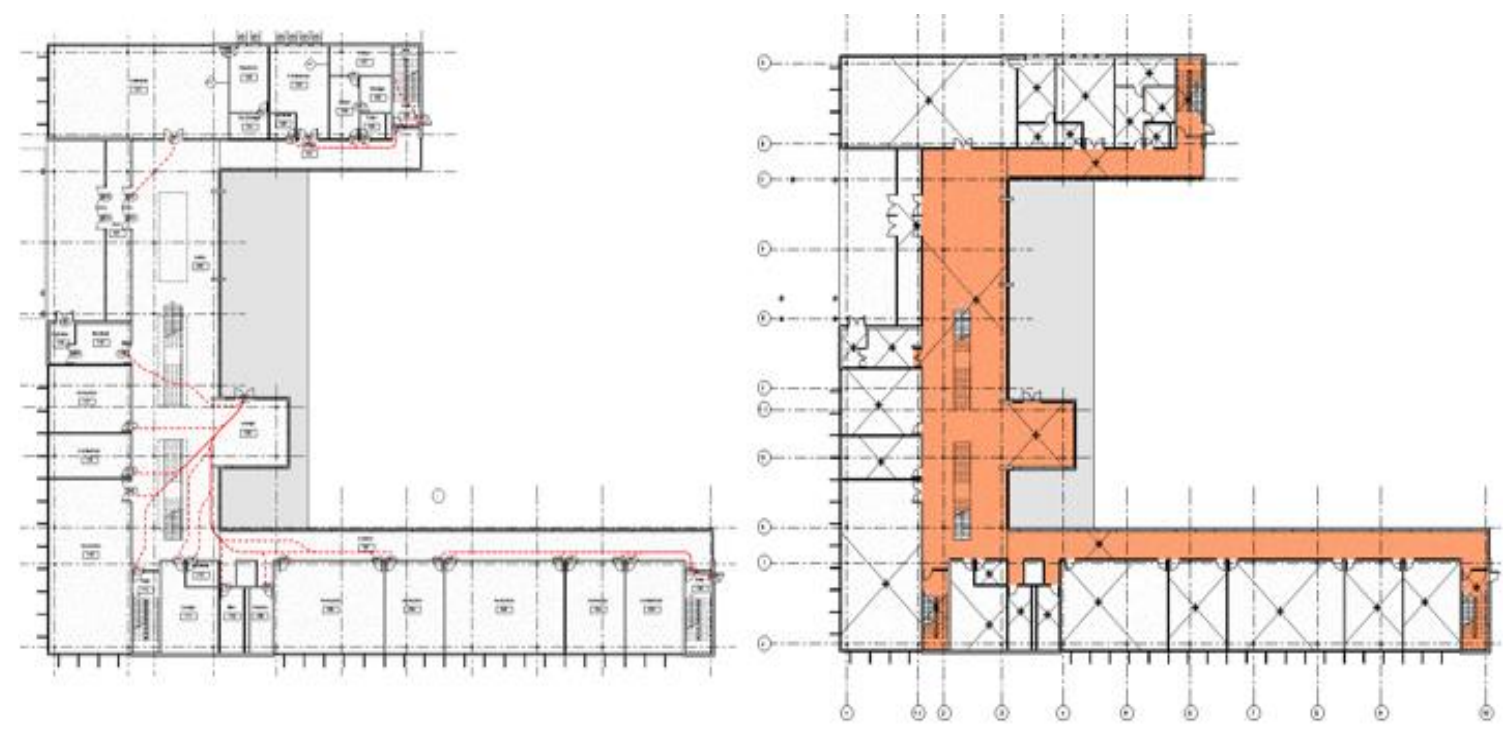

Figure 10. Escape route planning in Revit environment using an open API visual program.

\section{Discussion}

This research work presented a framework for construction fire safety planning using a visual algorithmic modeling approach to integrate firefighting equipment installation plans with construction fire safety planning. While previous studies in automated fire safety planning did not consider the rule-based equipment installation plan. The developed visual language and BIM-based con-fire safety planning (CSP) approach integrated firefighting equipment plan as an essential part of the construction fire safety. The case study test of a sample Revit project disclosed that the proposed approach leveraging visual language and BIM technology could provide more advanced and inclusive assessment for the rule-based construction fire safety planning. In order to prevent the fire risks in the construction job site, the designed approach has successfully developed the portable firefighting equipment installation plan semiautomatically, and in compliance with the OSHA guidelines.

Construction safety is not only limited to controlling and managing the safety behavior of the workers, but it also includes the design, procurement, and installation of the safety equipment such as guardrails, safety nets, scaffolding, and firefighting equipment. It is vital to be modeled in BIM for quantification and visualization purposes [36]. As the current fire safety planning practices in the construction industry follows the site-specific fire safety plan [33], which is time-consuming and labour-intensive if it is done with contemporary methods [35]. Based on the complexity and the scale of the project, the tedious modeling process generally needs days or even weeks [36]. However, as mentioned in the literature section, there are many software packages and approaches that can create sophisticated solutions to reduce the workload of the safety planner. This work also proposed a convenient approach to visualize the portable firefighting equipment and determine the actual cost estimation of the portable firefighting equipment with respect to the just on time approach. Hence, it is anticipated that the development of cost estimate plans could be cycle down from weeks to days or from days to even hours in some cases, depending on the size and complexity of the project. Moreover, the ambiguity of overestimating or underestimate can be eliminated, and the obtain cost information will be shared to others with great certainty. In this research work, the 2-D plan stair location, outline curve, interior walls need to be defined manually, automatic detection of 2D plan elements could be developed using space family tool in BIM environment, where the user does not need to define 2D plan elements and hence could be defined automatically. Moreover, to measure the travel distance trace length, the multi-agent simulation from the building corners towards the fire-extinguishers was out of the scope of this paper, and will be integrated with the future work. 


\section{Conclusions}

The growing challenges for fire safety concerning economic progress have encouraged the evolution of fire science and technology. Many researchers have currently developed building information modeling (BIM) technologies for construction safety planning to enhance safety in the pre-construction phase, such as checking the BIM model to prevent fall risks, BIM 4D-supported limited access zone identification and visualization, and excavation safety modeling. However, fire safety planning - mainly firefighting equipment planning-still relies on conventional methods and has not yet been appropriately explored. To address the issue, this research work offers rule-based construction fire safety planning using a visual language approach in BIM. The proposed approach includes three core modules, such as the RELD module, DCFS module, and CSPS module. The RELD module converts the OSHA fire safety rules into mathematical logic, and the DCFS module presents the development of the proposed approach, such as the conversion of rules from mathematical logic into computer language. The three sub-modules of the DCFS module visualize the results of the research work, for instance, generation of appropriate portable firefighting equipment planning, bill of quantities of firefighting equipment, and escape route plan. The CSPS module simulates the system into a common BIM environment. The developed fire safety rule-based approach has been successfully implemented in a sample project case study, and the vital benefits are summarized as follows.

a. It is found that the con-fire safety system semi-automatically generates and visualizes the portable firefighting equipment installation plan based on OSHA safety rules, which will minimize the workload and reduce the time of the safety planner. This research depicted that the proposed approach has significant potentials to enhance construction fire safety planning, which is inevitable to deal with the recently reported fatalities and property damages.

b. Integrating firefighting equipment installation plan with the escape route planning is a significant additional contribution of this study. It is anticipated that this approach would help decision-makers in developing practical fire safety plans. This full package of the construction fire safety planning and multi-agent simulation could also be used for the training of the workers and can be extended to the virtual contents by employing Virtual Reality (VR) technology.

c. Portable firefighting equipment installation was witnessed along with their quantity take-off and appropriate locations in the case study. Hence, the con-fire safety system can also predict the location coordinates and required fire preventive resource quantities in advance. Likewise, integrating this fire safety planning with BIM-4D will provide the cost based on the just-in-time approach.

Furthermore, the developed approach could open a new direction of research in the digital twin domain, such as integrating the multi-agent simulation with real humans and updating. In this way, the workers will understand the shortest path towards the fire extinguishers or outside, whatever the case may be. It is expected that the proposed approach has the potential to help designers in practical job sites.

Author Contributions: Conceptualization, N.K. and D.L.; methodology, N.K. and A.K.A.; software, A.K.A. and N.K.; validation, A.K.A., S.V.-T.T. and D.L.; formal analysis, C.P.; writing-original draft preparation, N.K.; writing — review and editing, N.K. and C.P.; visualization, X.X.; supervision, C.P.; project administration, D.L. All authors have read and agreed to the published version of the manuscript.

Funding: This research was supported by the Chung-Ang University research grant in 2018 and National Research Foundation of Korea (NRF) grant funded by the Korea government (MSIP) (No. NRF- 2019R1A2B5B02070721).

Conflicts of Interest: The authors declare no conflicts of interest.

\section{References}

1. Kumar, S.; Bansal, V.K. Construction safety knowledge for practitioners in the construction industry. J. Front. Constr. Eng. 2013, 2, 34-42. 
2. Mangement, L. The Importance Of Fire Safety on Construction Sites. Available online: https: //lifesafetymanagement.com/importance-fire-safety-construction-sites/ (accessed on 30 January 2020).

3. Rentals, U. Fire Extinguishers on Construction Sites: What's Required | United Rentals. Available online: https://www.unitedrentals.com/project-uptime/safety/fire-extinguishers-construction-sites-whatsrequired\#/ (accessed on 30 January 2020).

4. Campbell, R. Fires in structures under construction, undergoing major renovation or being demolished fact sheet. NFPA Res. Data Anal. 2017, 4, 1-11.

5. Shokouhi, M.; Nasiriani, K.; Cheraghi, Z.; Ardalan, A.; Khankeh, H.; Fallahzadeh, H. Preventive measures for fire-related injuries and their risk factors in residential buildings: A systematic review. J. Inj. Violence Res. 2019, 11, 1-14.

6. Guo, T.N.; Fu, Z.M. The fire situation and progress in fire safety science and technology in China. Fire Saf. J. 2007, 42, 171-182. [CrossRef]

7. Bureau of Labor Statistics National Census of Fatal Occupational Injuries in 2018-2019. Available online: https://www.bls.gov/news.release/pdf/cfoi.pdf (accessed on 3 February 2020).

8. Bureau of Labor Statistics Census of Fatal Occupational Injuries (CFOI) -Current and Revised Data. Available online: https://www.bls.gov/iif/oshcfoil.htm (accessed on 3 October 2018).

9. Gehandler, J. The theoretical framework of fire safety design: Reflections and alternatives. Fire Saf. J. 2017, 91, 973-981. [CrossRef]

10. Johnson, P.; Beyler, C.; Croce, P.; Dubay, C.; McNamee, M. Very early smoke detection apparatus (VESDA), David Packham, John Petersen, Martin Cole: 2017 dinenno prize. Fire Sci. Rev. 2017, 6, 1-12. [CrossRef]

11. Cram, D.; Hatch, C.E.; Tyler, S.; Ochoa, C. Use of distributed temperature sensing technology to characterize fire behavior. Sensors (Switzerland) 2016, 16, 1712. [CrossRef]

12. Kumm, M.; Bergqvist, A. Fire and rescue operations during construction of tunnels. Mälardalen University, Västerås, Sweden, Greater Stockholm Fire Brigade \& Karlstad University, Karlstad, Sweden. 2010. Available online: https://pdfs.semanticscholar.org/7638/c3d0c37ce0c79d54755964524ffda62b71aa.pdf (accessed on 3 February 2020).

13. Chen, Y.Y.; Chuang, Y.J.; Huang, C.H.; Lin, C.Y.; Chien, S.W. The adoption of fire safety management for upgrading the fire safety level of existing hotel buildings. Build. Environ. 2012, 51, 311-319. [CrossRef]

14. Yang, P.; Shi, C.; Gong, Z.; Tan, X. Numerical study on water curtain system for fire evacuation in a long and narrow tunnel under construction. Tunn. Undergr. Sp. Technol. 2019, 83, 195-219. [CrossRef]

15. Cheng, M.Y.; Chiu, K.C.; Hsieh, Y.M.; Yang, I.T.; Chou, J.S. Development of BIM-based real-time evacuation and rescue system for complex buildings. In Proceedings of the ISARC 2016-33rd International Symposium on Automation and Robotics in Construction, Auburn, AL, USA, 18-21 July 2016; pp. 999-1008.

16. Wang, S.H.; Wang, W.C.; Wang, K.C.; Shih, S.Y. Applying building information modeling to support fire safety management. Autom. Constr. 2015, 59, 158-167. [CrossRef]

17. Wang, K.C.; Shih, S.Y.; Chan, W.S.; Wang, W.C.; Wang, S.H.; Gansonre, A.A.; Liu, J.J.; Lee, M.T.; Cheng, Y.Y.; Yeh, M.F. Application of building information modeling in designing fire evacuation-a case study. In Proceedings of the ISARC 2014-31st International Symposium on Automation and Robotics in Construction and Mining, Sydney, Australia, 15 January 2014; pp. 593-601.

18. Maluk, C.; Woodrow, M.; Torero, J.L. The potential of integrating fire safety in modern building design. Fire Saf. J. 2017, 88, 104-112. [CrossRef]

19. Khan, N.; Ali, A.K.; Skibniewski, M.J.; Lee, D.Y.; Park, C. Excavation safety modeling approach using BIM and VPL. Adv. Civ. Eng. 2019, 2019, 1515808. [CrossRef]

20. Hossain, M.A.; Abbott, E.L.S.; Chua, D.K.H.; Nguyen, T.Q.; Goh, Y.M. Design for Safety knowledge library for BIM-integrated safety risk reviews. Autom. Constr. 2018, 94, 290-302. [CrossRef]

21. Liu, H.; Wang, Y.; Sun, S.; Sun, B. Study on safety assessment of fire hazard for the construction site. Procedia Eng. 2012, 43, 369-373.

22. Kumm, M.; Bergqvist, A. Fire and rescue operations during construction of tunnels. In Proceedings of the ISTSS-Fourth International Symposium on Tunnel Safety and Security, Frankfurt am Main, Germany, 17-19 March 2010; pp. 383-394. 
23. OSHA 1926.150 - Fire protection. I Occupational Safety and Health Administration. Available online: https://www.osha.gov/laws-regs/regulations/standardnumber/1926/1926.150 (accessed on 30 January 2020).

24. OSHA Commonly Used Statistics | Occupational Safety and Health Administration. Available online: https://www.osha.gov/data/commonstats (accessed on 31 January 2020).

25. Walnut Creek Personal Injury Lawyers Construction Site Fires-The Appel Law Firm. Available online: https://www.appellawyer.com/practice-areas/construction-accidents/construction-site-fires/ (accessed on 9 December 2019).

26. Chow, W.K. Fire safety in green or sustainable buildings: Application of the fire engineering approach in hong kong. Archit. Sci. Rev. 2003, 46, 297-303. [CrossRef]

27. Cygnus wireless alarm system Cygnus Wireless Fire Alarms | Construction Site Alarms. Available online: https://www.cygnusalarms.com/ (accessed on 12 December 2019).

28. Rüppel, U.; Schatz, K. Designing a BIM-based serious game for fire safety evacuation simulations. Adv. Eng. Inform. 2011, 25, 600-611. [CrossRef]

29. Chow, W.K. Performance-based approach to determining fire safety provisions for buildings in the Asia-Oceania regions. Build. Environ. 2015, 91, 127-137. [CrossRef]

30. Sztarbala, G. An estimation of conditions inside construction works during a fire with the use of computational fluid dynamics. Bull. Polish Acad. Sci. Tech. Sci. 2013, 61, 155-160. [CrossRef]

31. Fire emergency services Alaska. Contractor's Guide Safeguarding Construction/Demolition Operations from Fire Contractor's Guide; Fire emergency services Alaska: Anchorage, AK, USA, 2017; Volume 8, pp. 1-7.

32. Fire Safety Plan for Construction, Renovation and Demolition Sites Background Information. Edmont. Fire Rescue Serv. 2019, 11, 1-11.

33. Building, B.C.; Requirements, F.C. Fire safety plan guidelines for construction and demolition sites. City Colwood Fire Dep.-Fire Prev. Div. 2012, 1-4.

34. Choe, S.; Leite, F. Construction safety planning: Site-specific temporal and spatial information integration. Autom. Constr. 2017, 84, 335-344. [CrossRef]

35. Kim, K.; Lee, Y.C. Automated generation of daily evacuation paths in 4D BIM. Appl. Sci. 2019, 9, 1789. [CrossRef]

36. Zhang, S.; Sulankivi, K.; Kiviniemi, M.; Romo, I.; Eastman, C.M.; Teizer, J. BIM-based fall hazard identification and prevention in construction safety planning. Saf. Sci. 2015, 72, 31-45. [CrossRef]

37. Gambatese, J.A.; Hinze, J.W.; Haas, C.T. Tool to design for construction worker safety. J. Archit. Eng. 1997, 3, 32-41. [CrossRef]

38. Zhang, S.; Teizer, J.; Lee, J.K.; Eastman, C.M.; Venugopal, M. Building information modeling (BIM) and safety: Automatic safety checking of construction models and schedules. Autom. Constr. 2013, 29, 183-195. [CrossRef]

39. Gangolells, M.; Casals, M.; Forcada, N.; Roca, X.; Fuertes, A. Mitigating construction safety risks using prevention through design. J. Safety Res. 2010, 41, 107-122. [CrossRef]

40. Hadikusumo, B.H.W.; Rowlinson, S. Capturing safety knowledge using design-for-safety-process tool. J. Constr. Eng. Manag. 2004, 130, 281-289. [CrossRef]

41. Zhang, S.; Frank, B.; Jochen, T. Ontology-based semantic modeling of construction safety knowledge: Towards automated safety planning for job hazard analysis (JHA). Autom. Constr. 2015, 52, 29-41. [CrossRef]

42. Kim, H.; Lee, J.K.; Shin, J.; Choi, J. Visual language approach to representing KBimCode-based Korea building code sentences for automated rule checking. J. Comput. Des. Eng. 2019, 6, 143-148. [CrossRef]

43. Hongling, G.; Yantao, Y.; Weisheng, Z.; Yan, L. BIM and safety rules based automated identification of unsafe design factors in construction. Procedia Eng. 2016, 164, 467-472. [CrossRef]

44. Kim, K.; Teizer, J. Automatic design and planning of scaffolding systems using building information modeling. Adv. Eng. Inform. 2014, 28, 66-80. [CrossRef]

45. Lee, J. The automated design rule checking system. In Proceedings of the 24th International Conference on Computer-Aided Architectural Design Research in Asia: Intelligent and Informed, CAADRIA 2019, Wellington, New Zealand, 15-18 April 2019; Volume 1, pp. 795-804. 
46. Feng, C.W.; Lu, S.W. Using BIM to automate scaffolding planning for risk analysis at construction sites. In Proceedings of the ISARC 2017-34th International Symposium on Automation and Robotics in Construction, Taipei, Taiwan, 28 June-1 July 2017; pp. 610-617.

47. Payet, G. Developing a Massive Real-Time Crowd Simulation Framework on the Gpu. Bachelor's Thesis, University of Canterbury, Canterbury, UK, 2016. 